\title{
Quantification of purine basis in their mixtures at femto-molar concentration levels using FT-SERS
}

\author{
Vaclav Ranc, ${ }^{a *}$ Jana Hruzikova, $^{\mathrm{b}}$ Kamil Maitner, $^{\mathrm{b}}$ Robert Prucek, $^{\mathrm{c}}$ \\ David Milde ${ }^{b}$ and Libor Kvítek ${ }^{c}$
}

\begin{abstract}
Surface-enhanced Raman scattering spectroscopy represents one of the unique techniques for studying nanoscale objects, and its distinctive properties can be used in the process of further analysis. The careful evaluation of the particular influence of selected key-role experimental parameters (e.g. pH value of measured sample mixture, size and distribution of used nanoparticles) and the influence of reduction agent used in the process of formation of desired nanoparticle objects presents an important task in the further study of surface-enhanced Raman scattering effect. A broad study of these experimental parameters was performed in this paper. The main aim of the presented work was to a demonstrate an application potential of selected experimental conditions in the determination of three purine bases: adenine, xanthine, and hypoxanthine. The resulting limits of detection are at femtomolar concentration levels for all three studied compounds. Copyright $\odot 2011$ John Wiley \& Sons, Ltd.
\end{abstract}

Keywords: FT-SERS; adenine; hypoxanthine; xanthine; Raman spectrometry; nucleotides; nanoparticle

\section{Introduction}

Nanoscale objects, e.g. nanoparticles, can be studied using distinctive approaches and by many different more common or even uncommon procedures. Common techniques used for the study of physical and optical properties usually comprise scanning electron microscopy, ${ }_{1}^{[1]}$ transmission electron microscopy, ${ }^{[1-3]} \mathrm{dy}$ namic light scattering microscopy, ${ }_{1}^{[4]}$ or by, especially in last few years, the very popular atomic force microscopy. ${ }^{[5]}$ These techniques present a possibility to rapidly and easily characterize some of the key physical parameters of nanoparticles, e.g. their effective cross-section, density, surface characteristics or optical characteristics, respectively. Surface-enhanced Raman scattering (SERS) spectroscopy presents an interesting alternative substantially in the study of selected chemical properties of given nanoparticles at defined conditions.

Besides this assignment, SERS can also be employed in the study of various analytes of interest using nanoparticles as mediators for those actions. Signal enhancement using nanoparticles was described in detail, e.g. in the review by Smith et al. ${ }^{[6]}$

The study of experimental conditions is one of the key aspects of development of many methods utilizing SERS spectroscopy. The $\mathrm{pH}$ effect on surface charge and the resulting SERS spectra has been investigated using numerous chemical compounds, such as thiol molecules, ${ }^{[7-11]}$ imidazole, ${ }^{[12]}$ purine derivatives, ${ }^{[13]}$ cytosine and uracil, ${ }^{[14]}$ pyridines and acridines, ${ }_{1}^{[15,16]}$ isonicotinic acid $^{[17-19]}$ mercaptones, ${ }^{[20]}$ humic substances, ${ }^{[21]}$ lysozyme pigments, $^{[22]}$ dyes, ${ }^{[23]}$ pesticides, ${ }^{[24,25]}$ vitamins, ${ }^{[26]}$ food additives, ${ }^{[27]}$ nucleic acids, ${ }^{[28]}$ amino acids, ${ }^{[29-32]}$ proteins, ${ }^{[31,33-35]}$ ligands, ${ }^{[36]}$ lipids and lipolysis, ${ }^{[37-39]}$ and drug components. ${ }^{[26,40-43]}$ There even exist some studies on bacteria ${ }^{[44,45]}$ that have investigated the $\mathrm{pH}$ effect.

The effect of nanoparticles cross-sections and size distributions has been also evaluated, e.g. in the work by Mahmoud and Badr, ${ }^{[46]}$ where silver nanoparticles with various definite sizes were used. His investigation led to the important finding of nanoparticle size influence on the obtained enhancement factor and possible red shift. Another important work was performed by Glaspell et al., ${ }^{[4]}$ where nanoparticles in the range from 5 to $50 \mathrm{~nm}$ were studied, or by Nie et al., ${ }^{[48]}$ where single metal nanoparticles were evaluated. SERS effect was performed on Rhodamine $6 \mathrm{G}$. Link et al. ${ }^{[49]}$ also investigated the influence of the size of nanoparticles used for SERS experiments; temperature dependency was also investigated in this work. It was shown that not only nanoparticle size plays an essential role but also the temperature of the measured solution has a significant effect on the resulting enhancement factor obtained by SERS measurements.

Detection or a respective determination of nucleotides, nucleosides or their free bases present one of the continuously increasing important analytical tasks especially in the field of biochemistry, medicine, and related branches. ${ }^{[50,51]}$ Nucleic acids constituents present in the body fluids, tissues or cells can be products of nucleic acid catabolism, enzymatic degradation of tissues or unhealthy dietary habits. ${ }^{[52,53]}$ Alternation of tracked concentration levels of these compounds can also indicate some substantial deviances of activities of selected catabolic, anabolic or interconversion enzymes. Nucleic acid constituents can thus in some cases present effective markers of various diseases that cause alternations in the purine and pyrimidine metabolic pathways.

\footnotetext{
* Correspondence to: Vaclav Ranc, Department of Physiology, Faculty of Medicine University of Fribourg, Chemin du Musee 5, 1700 Fribourg, Switzerland. E-mail: vaclan.ranc@unifr.ch

a Department of Physiology, Faculty of Medicine, University of Fribourg, Chemin du Musee 5, Fribourg, CH1700, Switzerland

b Department of Analytical Chemistry, Faculty of Science, Palacky University Olomouc, 17. Listopadu 12, Olomouc, CZ77146, Czech Republic

c Regional Centre of Advanced Technologies and Materials, Department of Physical Chemistry, Faculty of Science, Palacky University, Slechtitelu 11, 78371, Olomouc, Czech Republic
} 
Analytical tasks dealing with an identification or determination of nucleic acids constituents are in most cases performed using capillary electrophoresis (e.g. Refs ${ }^{54-60}$ ), capillary electrochromatography ${ }^{[55]}$ or high performance liquid chromatography (HPLC, e.g. Refs ${ }^{61-65}$ ). These techniques offer high sample throughput connected with automation and robustness, and are financially efficient. One of the main problems of these techniques lies in their comparably higher detection limits.

Sheng et al. published a method for the determination of selected purine basis using RP-HPLC using real-time SERS spectroscopy. ${ }^{[66]}$ This method was based on the use of a separation technique (RP-HPLC) to separate target compounds and then, afterwards, SERS was used in an on-line detection technique. Analyzed concentration levels for target compounds were very good; they were in units of nmols per liter. This pilot work on an on-line approach introduced a possibility of using alternative analytical procedures (SERS) as detection systems. Development of methods targeted on the determination of selected analytes using SERS approaches present an interesting alternative to commonly used detection techniques but also have some significant limitations that have to be taken into account.

Du et al. developed a method based on SERS for the determination of melamine ${ }^{[67]}$ and it can be seen that the limit of detection is in the order of hundreds of micrograms per liter. However, the experimental design presents a complicated step and also the analysis of real samples presents a limitation. Quantification of target analytes using SERS has also been discussed, e.g. in the works by Barber et al., ${ }^{[68]}$ Cai et al.., ${ }^{[69]}$ Creighton, ${ }^{[70,71]}$ Lindgren and Larsson, ${ }^{[72,73]}$ and Xu et al. ${ }^{[72,73]}$

Koglin et al. described a method for the analysis of nucleic acid bases based on SERS effect established on the use of silver colloids. ${ }^{[7,75]}$ This work brought interesting results but the method, in its original setup, was not able to quantify an amount of respective compounds.

The main aim of this work is to develop an easy to use and effective method for the determination of selected bases: adenine, xanthine and hypoxanthine (for details see the Fig. 1).

\section{Experimental}

\section{Apparatus}

All spectroscopic experiments were performed using a Fourier transformation infrared spectroscopy instrument Nicolet 6700 with NXR accessory (Thermo - Electron, USA). The instrument was equipped with a germanium detector cooled by a liquid

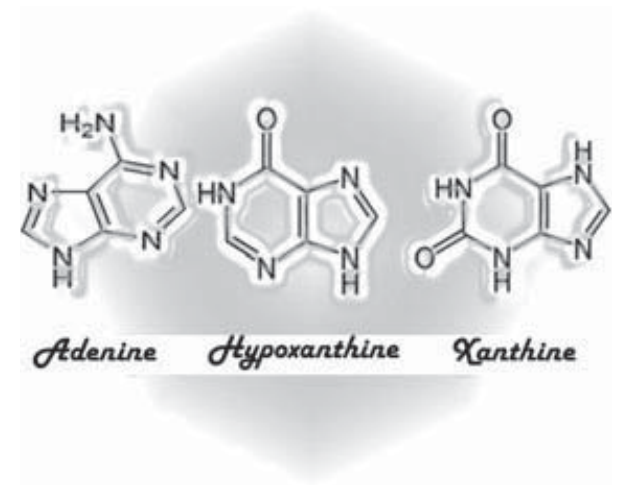

Figure 1. Schemes of analyzed compounds. nitrogen and Raman laser (NdYAG) with wavelength of $1064 \mathrm{~nm}$. Laser power was set to $100 \mathrm{~mW}$ (on sample) and the aperture was set to 150 (fully opened). The setting of experimental parameters was performed using a standard solution of adenine $\left(c=1 * 10^{-6} \mathrm{~mol} / \mathrm{L}\right.$ ) and all the relevant experimental parameters (laser power, aperture, gain, optical velocity) were set to obtain the most intense and time independent SERS spectroscopy signal. All experiments were repeated five times if not stated otherwise.

\section{Chemicals}

Adenine, xanthine, hypoxanthine, glucose, sodium citrate, and maltose (all pro analysis grade) were purchased from SigmaAldrich (San Jose, MA, USA). Silver nitrate, hydrochloric acid (36\%), ammonium hydroxide (24\%), and triethylamine (all pro analysis grade) were purchased from Fluka (part of Sigma-Aldrich, San Jose, USA). The water used was obtained from a Milli-Q water processing device (Millipore, USA) with conductivity less than $18 \mu \mathrm{S}$.

\section{Preparation of standard solutions}

Standard solutions of adenine, xanthine, and hypoxanthine were prepared by a precise and accurate weighting of $1 \mathrm{mg}$ of the corresponding base standard. The standard was dissolved in $1 \mathrm{ml}$ of deionized water giving concentration level of $1 \mathrm{mg} / \mathrm{mL}$. This solution mixture was diluted to desired concentration levels defined by calibration range.

\section{Preparation of nanoparticles}

Nanoparticles were synthesized using a modified procedure described by Kvitek et al., ${ }^{[76]}$ Soukupova et al., ${ }^{[77]}$ and Prucek et al. ${ }^{[78]}$ This procedure is based on the reduction of silver salt (silver nitrate is usually used) by a selected reduction agent (e.g. reduction sugar, sodium citrate, etc.) in a basic environment. This work uses silver nitrate (concentration $1 \mathrm{mg} / \mathrm{mL}$ ), where the silver is reduced using glucose $(c=10 \mathrm{mg} / \mathrm{mL})$, maltose $(c=10 \mathrm{mg} / \mathrm{mL})$ or citrate $(c=10 \mathrm{mg} / \mathrm{mL})$. The basic environment resulted from the addition of ammonium hydroxide $(0.1 \% \mathrm{v} / \mathrm{v}, \mathrm{pH}=10)$. Formed silver nanoparticles were stabilized using the addition of triethylamine $(c=10 \mathrm{mmol} / \mathrm{L})$.

\section{Preparation of working solutions}

Working solution mixtures were prepared as follows. Precisely $200 \mu \mathrm{L}$ of nanoparticles solution (60 ppm) was added to $690 \mu \mathrm{L}$ of deionized water. Then, $100 \mu \mathrm{L}$ of sodium chloride solution ( $c=100 \mathrm{mmol}$ ) was added and the mixture was vortexed. Finally, $10 \mu \mathrm{L}$ of analyte at corresponding concentration level was added. This solution was measured immediately.

\section{Results and Discussion}

\section{The study of selected experimental parameters}

First, SERS spectra for all respective compounds, namely xanthine, hypoxanthine, and adenine, were measured at the concentration level $1 \times 10^{-13} \mathrm{~mol} \cdot \mathrm{L}^{-1}$. The results can be seen in Fig. 2 . It is clear that the resulting SERS spectra differ and regions that are unique for selected compounds can be easily found.

Second, selected experimental parameters were taken into account. It is clear that the reduction agent used has a strong 


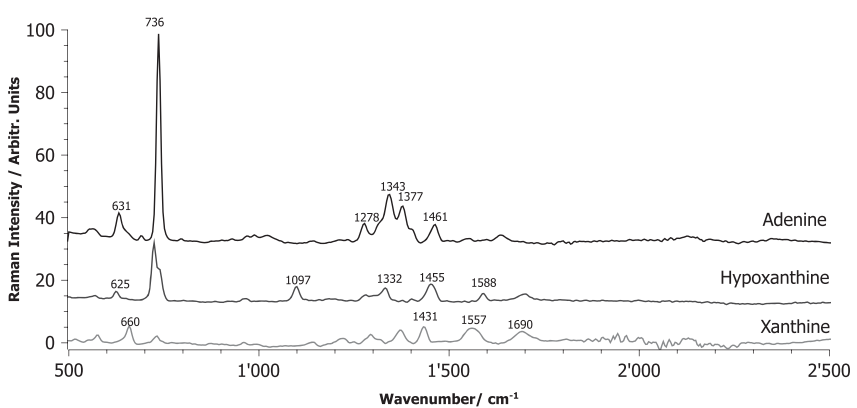

Figure 2. SERS spectra of adenine, hypoxanthine and xanthine measured at the concentration level $1 \times 10^{-13} \mathrm{~mol} \cdot \mathrm{L}^{-1}$.

influence on the resulting nanoparticle size and thus also on a significant number of the physical parameters by which the particle is defined. The main purpose of this work was to develop a SERS method for the analysis of selected nucleotides; thus, the influence of particle size on the resulting Raman peak areas has been evaluated. The obtained results are summarized in Table 1. It can be seen that the particle size (evaluated using dynamic light scattering microscopy) plays a significant role in the process of SERS spectroscopy measurements. Spectra obtained using glucose, maltose, and sodium citrate as reduction agents are shown in Fig. 3. It can also be seen that the use of sodium citrate and glucose led to similar results in contrast with the use of maltose that led to worse enhancement factors, outspread to this particular system and analytes. Another important parameter of the given nanoparticles is their stability in time. This factor was studied in the range of 10 days. Prepared nanoparticles were stored in the dark and at laboratory temperature for a given time and repeatedly used for SERS experiments (once every 2 days). The signal stability was studied. It was observed that the Raman signal decreases with time in the case of all selected silver nanoparticles. The study was based on the analysis of adenine $\left(c=1 \times 10^{-8} \mathrm{~mol} / \mathrm{L}\right)$. After a week of use, the signal was at half of its initial value in all cases of used reduction agents. Obtained data are shown in Fig. 4. A significant decrease of Raman intensity in time can be seen for all prepared types of nanoparticles (maltose, glucose, and sodium citrate were used as reduction agents). According to this situation, nanoparticles were prepared every working day from this point.

Table 1. Summary of the obtained experimental values. The highest peaks in the corresponding spectra were evaluated. The average particle side $(d)$ was obtained by dynamic light scattering microscopy

\begin{tabular}{|c|c|c|c|c|c|c|}
\hline \multirow[t]{2}{*}{$\begin{array}{l}\text { Reduction } \\
\text { agent }\end{array}$} & \multicolumn{2}{|c|}{$\begin{array}{c}\text { Glucose } \\
d=44 \mathrm{~nm}\end{array}$} & \multicolumn{2}{|c|}{$\begin{array}{c}\text { Citrate, } \\
d=58 \mathrm{~nm}\end{array}$} & \multicolumn{2}{|c|}{$\begin{array}{c}\text { Maltose } \\
d=28 \mathrm{~nm}\end{array}$} \\
\hline & AVG & STD & AVG & STD & AVG & STD \\
\hline \multicolumn{7}{|c|}{ Hypoxanthine, peak area at $730 \mathrm{~cm}^{-1}$} \\
\hline $\mathrm{PH} 7$ & 47.62 & 2.62 & 9.04 & 9.04 & 31.92 & 3.79 \\
\hline PH 10 & 40.85 & 2.48 & 14.41 & 3.86 & 18.48 & 5.12 \\
\hline \multicolumn{7}{|c|}{ Xanthine, peak at $660 \mathrm{~cm}^{-1}$} \\
\hline $\mathrm{PH} 7$ & 65.44 & 1.48 & 20.54 & 3.46 & 17.11 & 2.67 \\
\hline $\mathrm{PH} 10$ & 57.51 & 0.66 & 12.61 & 1.62 & 8.78 & 3.16 \\
\hline \multicolumn{7}{|c|}{ Adenine, peak at $736 \mathrm{~cm}^{-1}$} \\
\hline $\mathrm{PH} 7$ & 199.49 & 9.75 & 115.45 & 12.39 & 180.59 & 3.16 \\
\hline PH 10 & 171.78 & 15.85 & 112.74 & 21.55 & 121.44 & 75.69 \\
\hline
\end{tabular}

AVG, average of 5 experimental values; STD, standard deviation.

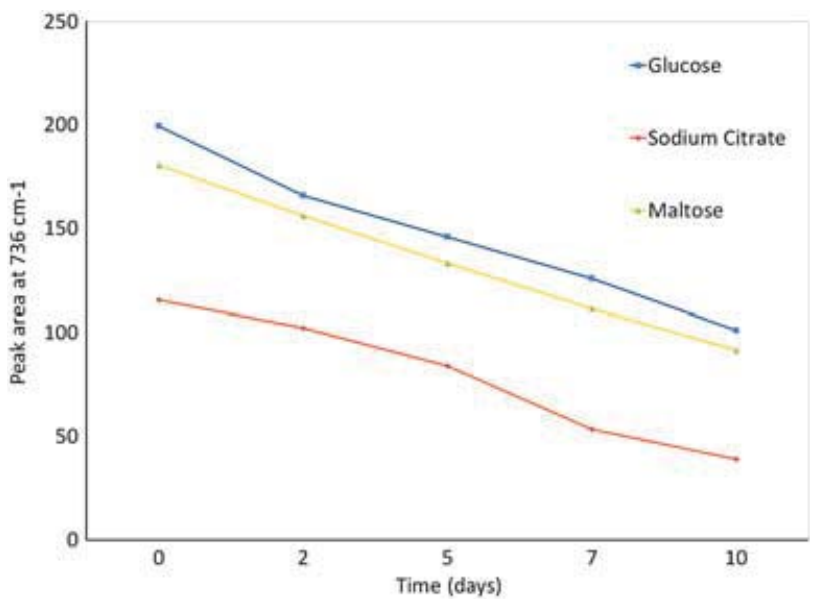

Figure 3. Dependency of selected Raman peak areas for respective compounds on time, $n=5$. Standard deviation of respective measurements is given by an error bar.

The third important parameter that was taken in account in this particular study is the influence of $\mathrm{pH}$ value of the measured sample mixtures. The influence of $\mathrm{pH}$ plays an important role in the case of proteolytic analytes, but has also some partial and not insignificant influence in other cases. It has been demonstrated that the state of a given analyte proteolytic balance influences the resulting SERS spectra mainly because a current proteolytic form of analyte, which is given by a $\mathrm{pH}$ value of environment, determines the method of its adsorption on silver nanoparticles. ${ }^{[79]}$ The study of the influence of $\mathrm{pH}$ value was performed using three different $\mathrm{pH}$ values of sample mixtures, $\mathrm{pH}=3,7$, and 10 . The value $\mathrm{pH}=3$ was obtained by the addition of hydrochloric acid $(c=50$ $\mathrm{mmol} / \mathrm{L}), \mathrm{pH} 7$ was a native $\mathrm{pH}$ of the initial solution and $\mathrm{pH} 10$ was obtained by the addition of ammonium hydroxide $(c=20$ $\mathrm{mmol} / \mathrm{L}$ ). For an illustration, Fig. 5 shows the analysis of adenine $\left(c=1 \times 10^{-8} \mathrm{~mol} / \mathrm{L}\right)$ at different $\mathrm{pH}$ values. Similar results were obtained for xanthine and hypoxanthine (data not shown). It was demonstrated that the addition of hydrochloric acid leads to a suppression of SERS signal. According to our best knowledge, the basic principles of SERS effect are still unknown but it can be seen that a shift of proteolytic balance can significantly influence a desired Raman spectrum. One of the possible causes can be the presence of positive charge on the heterogeneous nitrogen atom by which an analyte is adsorbed on a silver nanocomposite. On the other hand, higher $\mathrm{pH}$ values led to a significant increase of Raman signal, which supports our theory.

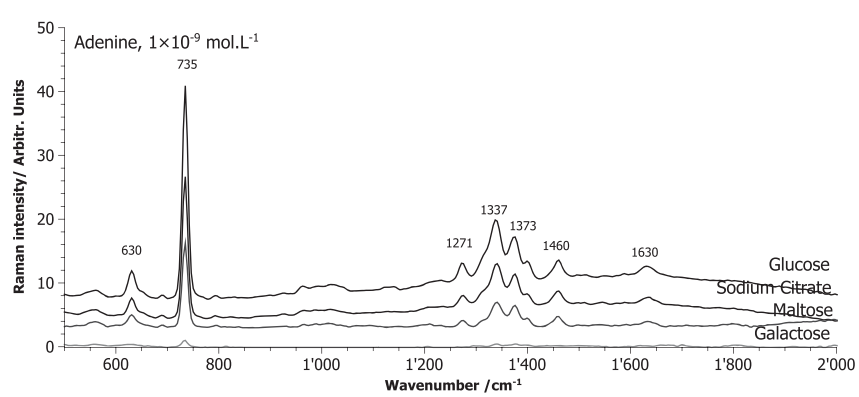

Figure 4. SERS spectra of adenine obtained for experiments where various reduction agents were used during the preparation of concrete nanoparticles. 


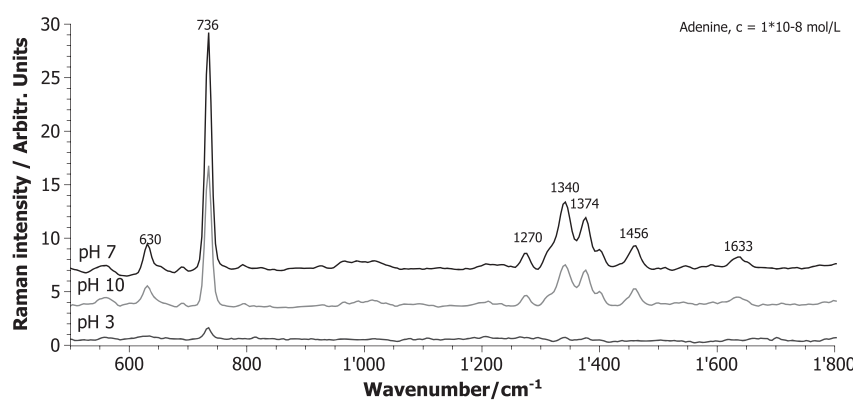

Figure 5. Influence of $\mathrm{pH}$ value of analyzed sample mixture on corresponding SERS spectra.

According to the results that were obtained during the study of experimental conditions, final conditions were selected and consequently used in the study of calibration parameters. The highest intensity of respective SERS signal was obtained with glucose as reduction agent of silver nitrate. Particles prepared using the mentioned reduction agent embodies suitable properties concerning the Raman enhancement factors and their stability in time. The best results were obtained using a $\mathrm{pH}$ value at $\mathrm{pH}=7$.

All obtained experimental values are summarized in the Table 1. The influence of selected experimental parameters, i.e. $\mathrm{pH}$ and reduction agent, was evaluated using peak area of the highest peak in the corresponding Raman spectrum. For adenine, the peak at $735 \mathrm{~cm}^{-1}$ was selected. This peak corresponds to a vibration of the $\mathrm{C}=\mathrm{N}$ bond in the purine ring. For hHypoxanthine, the peak that corresponds to a similar vibration was selected. It was located at $730 \mathrm{~cm}^{-1}$. In the case of xanthine, the peak at $660 \mathrm{~cm}^{-1}$ was selected. This peak was interpreted as the $\mathrm{C}=\mathrm{N}$ vibration on the pyrimidine ring.

\section{Calibration model design and evaluation}

The quantitative analysis was based on the evaluation of SERS spectroscopic data. For each target analyte, the highest peak in the corresponding spectrum was selected and taken into account. Its known that this approach is valid only in the narrow concentration rang and thus only a narrow interval of concentration levels was used. ${ }^{[80]}$ This limited validity is given mainly because of the concurrent adsorption of ballast species on the nanoparticle surface and by their limited surface (higher limit), and on the other side of the range there can be found serious problems with excitation laser incoherence and instrumental noise. However, it is possible to obtain qualification information using SERS experiments by a careful selection of experimental conditions and using defined and highly restricted concentration range. In an agreement with the mentioned possibilities, every evaluated spectrum was compared with the corresponding spectrum obtained by the analysis of a blank solution (working solution without an addition of analyte). In this way, the target peak in the analyte spectrum was compared with a corresponding peak in the blank spectrum and these two peaks were abstracted. The obtained reduced peak area was afterwards used for further evaluation. Every calibration level was measured five times if not stated otherwise.

Calibration levels for target compounds (adenine, xanthine, and hypoxanthine) were selected in the concentration range from $1 \times 10^{-15} \mathrm{~mol} / \mathrm{L}$ to $1 \times 10^{-8} \mathrm{~mol} / \mathrm{L}$ in ordered intervals (eight calibration levels). However, the linearity of calibration curves was obtained only in the lower part of this interval. For adenine,

\begin{tabular}{|c|c|c|c|c|c|c|}
\hline \multicolumn{6}{|c|}{ Calibration; $y=A x+B$} & \multirow{2}{*}{$\frac{\mathrm{LOD}}{\mathrm{mol} / \mathrm{L}}$} \\
\hline & $\mathrm{A}(\mathrm{mg} / \mathrm{L})$ & STD & $B(\mathrm{mg} / \mathrm{L})$ & STD & $R^{2}$ & \\
\hline Xantine & 0.82 & 0.01 & 3.44 & 0.21 & 0.99 & $2 \times 10^{-15}$ \\
\hline Hypoxantine & 1.82 & 0.02 & 213.74 & 1.25 & 0.92 & $1 \times 10^{-14}$ \\
\hline Adenine & 2.82 & 0.01 & 0.04 & 0.01 & 0.99 & $1 \times 10^{-15}$ \\
\hline
\end{tabular}

the linearity of the calibration curve was obtained in the range from $1 \times 10^{-15}$ to $1 \times 10^{-11} \mathrm{~mol} / \mathrm{L}$; for hypoxanthine and xanthine, this interval was from $1 \times 10^{-14}$ to $1 \times 10^{-10} \mathrm{~mol} / \mathrm{L}$, respectively.

The curvature of the calibration curves at higher concentration levels could be caused, e.g. by concurrent adsorption processes on the limited surface of nanoparticles described above.

The limits of detection (LOD) were calculated from the obtained spectra. Measured data were compared with corresponding blank spectra and after subtraction, LOD was calculated from the highest peak in the given reduced spectrum using an approach that is based on the signal-to-noise ratio. The summary of the obtained results can be seen in the Table 2 .

\section{Analysis of model mixtures}

The analysis of model mixtures was based on the similar approaches that have been used in the calibration model design. Samples containing all three target compounds on the selected concentration levels were measured. These concentration levels were selected according to the results that were obtained in the process of calibration model development. For all three target compounds (adenine, xanthine, and hypoxanthine), these levels were $1 \times 10^{-12}$ and $1 \times 10^{-13} \mathrm{~mol} / \mathrm{L}$ of the respective target compound. A new mixture calibration model has also been constructed. This calibration model was based on the analysis of the mixture containing all three targets: xanthine, hypoxanthine, and adenine. The calibration range was selected from $1 \times 10^{-15}$ to $1 \times 10^{-10} \mathrm{~mol} / \mathrm{L}$. For each target compound, its unique peak was found. The selection criteria for these peaks were based on two prerequisites: first, the selected peak has to be unique for a target compound and second, this peak has to be intense enough for quantification purposes at femtomolar concentration levels. For adenine, the peak at $735 \mathrm{~cm}^{-1}$ was used; for hypoxanthine, the peak at $1097 \mathrm{~cm}^{-1}$ was used; and for xanthine, the peak at $660 \mathrm{~cm}^{-1}$ was selected. On the basis of these principles, calibration curves for each target compound were constructed. Calibrations were linear in the whole selected ranges for all three compounds. The spectrum obtained by the analysis of the sample containing $1 \times 10^{-12} \mathrm{~mol} / \mathrm{L}$ of target compounds can be seen in the Fig. 6 . Two model samples containing $1 \times 10^{-12}$ and $1 \times 10^{-11} \mathrm{~mol} / \mathrm{L}$ of all target compounds were prepared to test the calibration. Results obtained by the analysis of these model samples are given in the Table 3. It can be seen that the analysis of sample mixtures brought some difficulties that were reflected in a relatively lower obtained correlation coefficients (compared with an analysis of standards), but the method is suitable for a screening analysis of selected compounds in the mixture on very low concentration levels. 


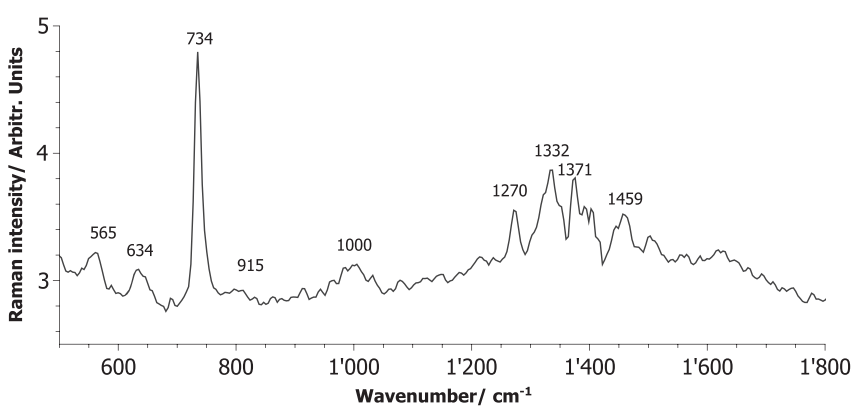

Figure 6. SERS spectrum of the mixture of target analytes: adenine, hypoxanthine, and xanthine, $c=1 \times 10^{-12} \mathrm{~mol} / \mathrm{L}$.

Table 3. The summary of results obtained by an analysis of model sample mixtures, RSD stands for relative standard deviantion.

\begin{tabular}{|lcccccc|} 
& $\begin{array}{c}\text { Sample A RSD } \\
{[\mathrm{mol} / \mathrm{L}]} \\
10^{-13}\end{array}$ & $\begin{array}{c}\text { Difference } \\
{[\mathrm{mol} / \mathrm{L}]} \\
10^{-13}\end{array}$ & $\begin{array}{c}\text { Sample B RSD } \\
{[\mathrm{mol} / \mathrm{L}]} \\
10^{-13}\end{array}$ & $\begin{array}{c}\text { Difference } \\
{[\%]}\end{array}$ & $\begin{array}{c}\mathrm{mol} / \mathrm{L}] \\
10^{-12}\end{array}$ \\
\hline Adenine & 9.5 & 4.5 & 0.5 & 98 & 5.1 & 2 \\
Xanthine & 7.2 & 5.5 & 2.8 & 105 & 5.2 & 5 \\
Hypoxanthine & 14.9 & 4.8 & 4.9 & 108 & 4.8 & 8 \\
\hline
\end{tabular}

\section{Concluding Remarks}

A method for the analysis of model sample mixtures of selected nucleotides was developed. This method is based on the use of SERS spectroscopy with Fourier transformation. Adenine, hypoxanthine, and xanthine were selected as model analytes. The obtained limits of detection are in the units of femtomols for adenine and xanthine and in tens of femtomols for hypoxanthine. By the analysis of model sample mixtures containing all three selected compounds, it was shown that the obtained RSD is on average $5 \%$ (from $4.5 \%$ to $5.5 \%$ ) for both selected model samples.

\section{Acknowledgements}

The authors gratefully acknowledge the support of the Operational Program Research and Development for Innovations European Regional Development Fund (Project No. CZ.1.05/ 2.1.00/03.0058 of the Ministry of Education, Youth and Sports of the Czech Republic).

\section{References}

[1] E. D. Cabanillas, M. S. Granovsky, M. J. Ratner, Acta Microsc. 2010, 19(2), 190-195.

[2] P. Fredrickx, D. Helary, D. Schryvers, E. Darque-Ceretti, Appl Phys aMater 2004, 79(2), 283-288.

[3] T. J. Bromwich, D. G. Bucknall, B. Warot, A. K. Petford-Long, C. A. Ross, Inst. Phys. Conf. Ser. 2004, 21(179), 95-98.

[4] D. Chicea, Optoelectron. Adv. Mat. 2010, 4(9), 1310-1315.

[5] S. Kim, F. Shafiei, D. Ratchford, X. Q. Li, Nanotechnology 2011, 22(11), $1-6$.

[6] W. E. Smith, G. McNay, D. Eustace, K. Faulds, D. Graham, Appl. Spectrosc. 2011, 65(8), 825-837.

[7] R. Langer, C. Wang, N. T Flynn, Adv. Mater. 2004, 16(13), 1074-1079.

[8] G. N. R. Tripathi, M. Clements, J. Phys. Chem. B 2003, 107(40), 11125-11132.

[9] Q. J. Meng, W. W. Zhang, X. M. Ren, H. F. Li, C. S. Lu, C. J. Hu, H. Z. Zhu, $J$ Colloid Interf Sci 2002, 255(1), 150-157.

[10] R. L. Garrell, C. A. Szafranski, W. Tanner, P. E. Laibinis, Langmuir 1998 14(13), 3580-3589.
[11] A. T. Hubbard, J. Y. Gui, J Chim Phys Pcb 1991, 88(7-8), 1547-1590.

[12] W. S. Yang, J. Guan, L. Jiang, J. Li, J. Phys. Chem. C 2008, 112(9), 3267-3271.

[13] J. G. Duguid, V. A. Bloomfield, J. M. Benevides, G. J. Thomas, Biophys. J. 1995, 69(6), 2623-2641.

[14] G. R. Loppnow, B. E. Billinghurst, S. A. Oladepo, J. Phys. Chem. B 2009, 113(20), 7392-7397.

[15] G. Levi, J. Pantigny, J. P. Marsault, J. Aubard, J. Raman Spectrosc. 1993, 24(11), 745-752.

[16] S. T. Oh, K. Kim, M. S. Kim, J Phys Chem-Us 1991, 95(22), 8844-8849.

[17] Y. Fang, R. Wen, J Colloid Interf Sci 2005, 292(2), 469-475.

[18] S. M. Park, K. Kim, M. S. Kim, J. Mol. Struct. 1995, 344(3), 195-203.

[19] S. M. Park, K. Kim, M. S. Kim, J. Mol. Struct. 1994, 328, 169-178.

[20] I. M. Weidinger, M. Sezer, J. J. Feng, H. K. Ly, Y. F. Shen, T. Nakanishi, U. Kuhlmann, P. Hildebrandt, H. Mohwald, Phys. Chem. Chem. Phys. 2010, 12(33), 9822-9829.

[21] M. M. Campos-Vallette, P. Leyton, I. Cordova, P. A. Lizama-Vergara, J. S. Gomez-Jeria, A. E. Aliaga, E. Clavijo, J. V. Garcia-Ramos, S. Sanchez-Cortes, Vib. Spectrosc. 2008, 46(2), 77-81.

[22] M. Breitman, S. Ruiz-Moreno, R. Perez-Pueyo, J. Cult. Herit. 2003, 4, $314 s-316 s$

[23] Z. L. Zhang, D. H. Chang, Y. J. Mo, Spectroscopy-Us 2011, 26(6), 38-42.

[24] S. Li, F. Y. Ji, D. N. Yu, G. M. Zhou, Q. A. He, Acta Chim Sin. 2010, 68(16), 1616-1622.

[25] J. S. Kang, S. Y. Hwang, C. J. Lee, M. S. Lee, B Kor Chem Soc 2002, 23(11), 1604-1610.

[26] S. C. Pinzaru, I. Pavel, N. Leopold, W. Kiefer, J. Raman Spectrosc. 2004, 35(5), 338-346.

[27] E. Podstawka, M. Swiatlowska, E. Borowiec, L. M. Proniewicz, J. Raman Spectrosc. 2007, 38(3), 356-363.

[28] S. Sanchezcortes, J. V. Garciaramos, J. Mol. Struct. 1992, 274, 33-45.

[29] G. M. Zhou, D. N. Yu, S. Li, D. C. Yang, Acta Chim Sin. 2007, 65(7), 640-644.

[30] W. Z. Ke, J. Z. Wu, Spectrosc Spect Anal 2004, 24(5), 551-553.

[31] X. M. Dou, Y. M. Jung, H. Yamamoto, S. Doi, Y. Ozaki, Appl. Spectrosc. 1999, 53(2), 133-138.

[32] H. Lee, M. S. Kim, S. W. Suh, J. Raman Spectrosc. 1991, 22(2), 91-96.

[33] M. losin, V. Canpean, S. Astilean, J Photoch Photobio A 2011, 217(2-3), 395-401.

[34] P. Leyton, P. A. Lizama-Vergara, M. M. Campos-Vallette, M. I. Becker, E. Clavijo, I. C. Reyes, M. Vera, C. A. Jerez, J. Chil. Chem. Soc. 2005, 50(4), 725-730.

[35] R. P. Van Duyne, L. A. Dick, A. J. Haes, J. Phys. Chem. B 2000, 104(49), 11752-11762.

[36] D. M. Zhang, S. M. Ansar, R. Haputhanthri, B. Edmonds, D. Liu, L. Y. Yu, A. Sygula, J. Phys. Chem. C 2011, 115(3), 653-660.

[37] S. H. Oh, K. C. Bantz, A. F. Meyer, N. J. Wittenberg, H. Im, O. Kurtulus, S. H. Lee, N. C. Lindquist, C. L. Haynes, Phys. Chem. Chem. Phys. 2011, 13(24), 11551-11567.

[38] M. D. Morris, M. K. Weldon, Appl. Spectrosc. 2000, 54(1), 20-23.

[39] M. D. Morris, M. K. Weldon, V. R. Zhelyaskov, Appl. Spectrosc. 1998, 52(2), 265-269.

[40] S. Sanchez-Cortes, I. Izquierdo-Lorenzo, J. V. Garcia-Ramos, Langmuir 2010, 26(18), 14663-14670.

[41] S. Farquharson, A. D. Gift, C. Shende, P. Maksymiuk, F. E. Inscore, J. Murran, Vib. Spectrosc. 2005, 38(1-2), 79-84.

[42] S. Sanchez-Cortes, L. Rivas, A. Murza, J. V. Garcia-Ramos, Vib. Spectrosc. 2001, 25(1), 19-28.

[43] S. Farquharson, Y. H. Lee, Biochem. Biomol. Sen. 2000, 4200, 89-95.

[44] T. Smith-Palmer, M. Kazanci, J. P. Schulte, C. Douglas, P. Fratzl, D. Pink, Appl. Spectrosc. 2009, 63(2), 214-223.

[45] Y. R. Chen, Y. L. Liu, X. W. Nou, K. L. Chao, Appl. Spectrosc. 2007, 61(8), 824-831.

[46] M. A. Mahmoud, Y. Badr, J. Mol. Struct. 2005, 749(1-3), 187-192.

[47] G. P. Glaspell, C. Zuo, P. W. Jagodzinski, Abstr Pap Am Chem S 2001, 221, U279-U279.

[48] E. Sr, W. E. Haskins, S. M. Nie, J. Am. Chem. Soc. 1998, 120(31), 8009-8010.

[49] S. Link, L. Slaughter, W. S. Chang, J. Phys. Chem. Lett. 2011, 2(16), 2015-2023.

[50] G. M. Blackburn, Nucleic acids in chemistry and biology, (3rd ed.), RSC Pub., Cambridge, UK, 2006; p xxxi, p. 470

[51] Nucleosides, nucleotides \& nucleic acids. In Marcel Dekker, Monticello, N.Y., 2000; p v. 
[52] P. Illes, H. Zimmermann, Nucleotides and their receptors in the nervous system. (1st ed.), Elsevier Science, Amsterdam; New York, 1999; p xvi, p. 432

[53] L. Belardinelli, A. Pelleg, Adenosine and adenine nucleotides: from molecular biology to integrative physiology, Kluwer Academic Publishers, Boston, 1995; p xix, p. 543

[54] B. Vester, H. Doessing, Molecules 2011, 16(6), 4511-4526.

[55] S. P. Li, X. J. Chen, F. Q. Yang, Y. T. Wang, Electrophoresis 2010, 31(13), 2092-2105.

[56] A. E. Barron, C. P. Fredlake, D. G. Hert, E. R. Mardis, Electrophoresis 2006, 27(19), 3689-3702.

[57] J. F. Van Bocxlaer, A. V. Willems, D. L. Deforce, C. H. Van Peteghem, Electrophoresis 2005, 26(7-8), 1221-1253.

[58] E. Bayer, A. von Brocke, G. Nicholson, Electrophoresis 2001, 22(7), 1251-1266.

[59] A. Harsch, C. L. Andrews, P. Vouros, J. Chromatogr. A 1999, 856(1-2), 515-526.

[60] N. W. Smith, M. B. Evans, J Pharmaceut Biomed 1994, 12(5), 579-611.

[61] F. Toldra, L. Mora, A. S. Hernandez-Cazares, M. C. Aristoy, M. Reig, Food Anal Method 2011, 4(1), 121-129.

[62] A. Kohen, K. A. Markham, Curr. Anal. Chem. 2006, 2(4), 379-388.

[63] M. O'Regan, Neurol. Res. 2005, 27(2), 175-181.

[64] W. F. Smyth, Trac-Trend Anal Chem 1999, 18(5), 335-346.

[65] B. J. Smith, M. R. Wales, M. J. Perry, Appl Biochem Biotech 1993, 41(3), 189-218.

[66] R. S. Sheng, F. Ni, T. M. Cotton, Anal. Chem. 1991, 63(5), 437-442.
[67] X. B. Du, H. Y. Chu, Y. W. Huang, Y. P. Zhao, Appl. Spectrosc. 2010, 64(7), 781-785.

[68] T. E. Barber, M. S. List, J. W. Haas, E. A. Wachter, Appl. Spectrosc. 1994, 48(11), 1423-1427.

[69] W. B. Cai, X. K. Xue, S. J. Huo, Y. G. Yan, J. Y. Wang, J. L. Yao, Acta Chim Sin. 2007, 65(15), 1437-1442.

[70] J. A. Creighton, Surf. Sci. 1983, 124(1), 209-219.

[71] J. A. Creighton, Surf. Sci. 1986, 173(2-3), 665-672.

[72] J. Lindgren, M. Larsson, J. Raman Spectrosc. 2005, 36(5), 394-399.

[73] H. X. Xu, E. J. Bjerneld,J. Aizpurua, P. Apell, L. Gunnarsson, S. Petronis, B. Kasemo, C. Larsson, F. Hook, M. Kall, Nanoparticles and Nanostructured Surfaces: Novel Reporters with Biological Applications 2001, 2 (15), 35-42.

[74] E. Koglin, J. M. Sequaris, J. C. Fritz, P. Valenta, J. Mol. Struct. 1984, 114(MAR), 219-223.

[75] E. Koglin, J. M. Sequaris, P. Valenta, J. Mol. Struct. 1982, 79(1-4), 185-189.

[76] L. Kvitek, R. Prucek, A. Panacek, J. Soukupova, M Vanickova, Nanocon 2009, Conference Proceedings 2009, 74-82.

[77] J. Soukupova, L. Kvitek, A. Panacek, T. Nevecna, R. Zboril, Mater. Chem. Phys. 2008, 111(1), 77-81.

[78] R. Prucek, A. Panacek, A. Fargasova, V. Ranc, V. Masek, L. Kvitek, R. Zboril, CrystEngComm 2011, 13(7), 2242-2248.

[79] X. M. Dou, Y. M. Jung, Z. Q. Cao, Y. Ozaki, Appl. Spectrosc. 1999, 53(11), 1440-1447.

[80] P. D. O'Neal, G. L. Cote, M. Motamedi, J. Chen, W. C. Lin, J. Biomed. Opt. 2003, 8(1), 33-39. 